\title{
Literary Theory as a Corrective in National Cultures
}

\author{
HARVEY LEE HIX
}

Instead of purporting to prove a proposition, I will point to a pattern: it will identify three seemingly unrelated phenomena, and, by noticing a resemblance between them, describe them as three varieties of one species, three tokens of a larger type. Instead of sequencing premises that entail a conclusion, it will array observations to invite a gestalt. Because each item described (the three varieties and the species) has both a textual and a social aspect, each acts as a contact point at which literary theory and national culture bear on one another. Collectively, the cases indicate one role for literary theory: it should, and does, function as a corrective in relation to national culture.

Three short texts, then, as a starting point.

A verse from a contemporary English-language translation of a Biblical Gospel. This is Matthew 9:28 in the New American Standard Bible: "And after He had come into the house, the blind men came up to Him, and Jesus said to them, 'Do you believe that I am able to do this?' They said to Him, 'Yes, Lord.'”

The fourth amendment to the U.S. Constitution, part of what is called The Bill of Rights: "Article the fourth... A well regulated Militia, being necessary to the security of a free State, the right of the people to keep and bear Arms, shall not be infringed."

The campaign slogan employed in the 2016 U.S. presidential election by the candidate who was elected that year: "Make America Great Again."

The gospel passage exemplifies what I call translation inertia, the constitutional amendment exemplifies what I call aspect asynchrony, and the political slogan exemplifies what I call yesternationalism. The three passages might seem unrelated, but juxtaposing them draws out a commonality, revealing each as an instance of what I call signostalgia.

\section{Translation Inertia}

The issue to which I want to draw attention in the translated Gospel passage is its choice of the word "Lord." The sentence "They said to Him, 'Yes, Lord"” 


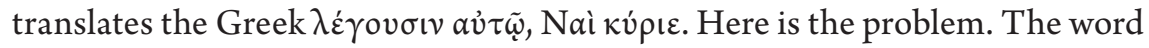
кúpı in the original language is not a proper noun, but the word Lord in the translation is. The Greek word is a term of respect or deference, an honorific, a form of address but not a title or a proper name. A more natural and more apt translation would be, "They said to Him, Yes, sir," but no one has translated it that way. There have been countless translations of the canonical Gospels into English since the King James version (one of the earliest translations into English and by far the most influential); to my knowledge, every one of those translations uses Lord for the Greek kurios.

This is an instance of what I call translation inertia because the English word "lord" has changed radically in its meaning since 1611, when the King James version of the Bible was published, so it no longer correlates with kurios in the way that it once did, yet, despite that lack of correlation, it continues to be used in translations. Translation inertia occurs when a word in the target language continues to be used as a correlative for a word in the source text even after the meaning of the word in the target language has changed. "Translation inertia," then, designates the tendency to replicate in later translations word choices from earlier translations because they are now familiar, rather than because they are still apt.

Translating kurios with Lord had a certain resonance in England at the time of King James, when "Lord" was a familiar title, one in current use, but a contemporary U.S. citizen, say, has no daily-life reference point for a "lord." To the original audience of the Greek Gospels, there was a sense of the word kurios that preceded its application to Jesus. For example, the same word is also applied to the Roman official Pontius Pilate, and to the householder in the parable of the laborers in the vineyard: they are called kurios just like Jesus is. The Greek word was very common, used in many contexts and in reference to many persons. At the time of King James, the English word "lord" also was used in various contexts and in reference to various persons, but to contemporary English speakers the word refers exclusively to Jesus. A speaker in England in 1611 might reply to a person of higher social standing with "Yes, Lord," as an indication of deference, but in the U.S. in 2019 anyone replying to anyone else with "Yes, Lord" would sound absurd. This is because in 1611 in England the word "lord" acknowledged the relative positions of speaker and spoken-of along a continuum of human social standing: wealth, class, political power. A tenant farmer in replying "Yes, Lord" to the owner of the land he farms would be acknowledging that the landowner is wealthier, occupies a higher social class, and has power over him. The Provost of the university in which I am employed has a higher salary than I do, belongs to a higher social class, and has power over me. But I could not acknowledge that difference in social standing 
by replying to her with "Yes, Lord": the word "lord" simply does not function in that way now. The word "lord" is no longer an acknowledgment of relative social standing, but a designation of metaphysical standing: it is an attribution of divinity.

I call this translation inertia because in 1611 there was strong correlation between the English word lord and the Greek word kurios: both were common terms that could be applied to various persons, and both acknowledged differences in social standing. Now, though, the word "lord" has neither of those features: it no longer correlates in those essential ways with, yet it continues to be used as a translation for, kurios.

\section{Aspect Asynchrony}

By contrast with the Biblical passage, the amendment to the U.S. Constitution does not involve translation. Still, it involves an interpretive difficulty. The word "arms" exemplifies "aspect asynchrony," by which I mean that the various constituents of the meaning of a word need not change at the same pace. By the constituents of meaning, I refer to such features of a word as its context and usage. In the case of "arms," context has changed faster than usage.

The U.S. Bill of Rights, which includes the declaration that "the right of the people to keep and bear Arms, shall not be infringed," was ratified in 1791. Since then, the context of the word "arms" has changed significantly, and with that changed context the connotations of the word have changed. In 1791, guns had to be reloaded before each shot, a process that involved pouring powder down the barrel, packing it, and adding by hand a metal ball as the projectile. Technological developments since then include breech loading (bullets), the revolver, and automatic weapons. The number and variety of items designated by the word "arms" has greatly increased since the Bill of Rights was written, and the capacities granted by bearing arms have changed radically. In 1791, arms granted a bearer the capacity to kill one person at a time, with a long pause necessary to reload. Today, arms can, and many arms do, grant a bearer the capacity to kill very many persons consecutively, with essentially no pause in between. An M-16, for example, can fire at a rate of over 700 rounds per minute. In 1791 bearing arms did not enable an individual to commit mass murder, but today it does.

The usage of the word has not changed swiftly enough to keep up: it is still used most often in the very phrase that appears in the constitutional amendment, "keep and bear arms," and it is used most often as if the capacity enhanced by arms were primarily defense, even though the context has changed so that the arms available now enhance offensive capability much more radically than they enhance defensive capability. 
HIX

\section{Yesternationalism}

Though less exalted than a scriptural text or a constitutional text, a political slogan nonetheless is, like them, granted authority by its adherents, so let me add one to consideration here. In the 2016 U.S. presidential campaign, Donald Trump employed the slogan "Make America Great Again," a slight variant of the slogan that Ronald Reagan had employed in the 1980 campaign, "Let's make America great again." Both slogans appeal to, and exemplify, what I am calling "yesternationalism." The word "America" is the same now as it was in 1791 when the Bill of Rights was ratified, and the same as it was in 1865 when the Civil War ended, and the same as it was in 1945 at the end of World War II, but the referent of "America," the nation designated by that word, has changed over that time. The yesternationalist mistakes the continuity of the nation across time for the identity of the nation over time.

Similar confusion of continuity with identity occurs when an individual trying to recover lost youth declares, "I'm still the same person I always was." The declaration equivocates on two meanings: "I am continuous with the person I was at age 20," and "I am identical to the person I was at age 20." One of those meanings is true, but the other is false. Analogously, "Make America Great Again” equivocates. The U.S. of 2019 is continuous with the U.S. of, say, 1945 , but it is not identical to that U.S. The contemporary U.S. has more than twice as many people as the U.S. of 1945, for example, and has 50 states now but had 48 then. What "America" is now, and what would make this "America" "great" do not match what "America" was then, and what purportedly made it "great" then. The "again" in the slogan can deceive the slogan's adherents, because the "America" has already deceived them.

\section{Signostalgia}

Now, the point. However unlike they may be in other respects, the Biblical translation, constitutional amendment, and political slogan share at least one feature, what I call signostalgia. All three bungle this broad interpretive problematic: the words themselves of a text stay fixed, but the meanings of the words change over time. Ignoring or denying the effects of that difference invites error.

If I am editing Shakespeare's Hamlet, I want to keep exactly the same words Shakespeare himself used, as when he has Hamlet declare to Ophelia, "I am myself indifferent honest." Those were the words of the text then, and they are still the words of the text now. But if I am reading the play, it helps to know that "indifferent," which now means unconcerned or disinterested, in Shakespeare's time meant average; and "honest," which now has to do with truth-telling, in 
Shakespeare's time had to do with virtue more broadly, and foregrounded sexual virtue. The words themselves have stayed the same, but the meaning of the words has changed over time. The signifiers are fixed, the signifieds fluid.

Consequently, for a written text of any age, what it says and what it means are not identical, and the relationship between what it says and what it means is not static. What it says (what its words are) is of the two by far the easier to establish and agree upon. Regarding what the text says, we can approximate certainty and consensus. What the text means, though, is far harder to establish, and harder to agree upon.

Signostalgia is motivated: of course we wish we could secure for what the text means the same certainty and consensus we can secure for what the text says. We cannot, but we succumb to signostalgia when we act as if we could. The signostalgist does not recognize the difference between what the text says and what it means. By eliding the two, the signostalgist secures the belief that there is certainty, and ought to be consensus, about what the text means. Each of the three example cases just given is a manifestation of signostalgia: exclusive loyalty to the fixed word, in denial of its changing meaning. The consequences of signostalgia show up with particular clarity when the text in question is considered authoritative (sacred texts, founding documents, and so on), because in such cases special pressure is put on the text's capacity to shape identity and guide behavior. Signostalgia secures me in the consoling belief that the text means now what it has always meant.

\title{
Theory and Culture
}

Identifying signostalgia highlights one role literary theory performs in national culture. By inhabiting and exploring and describing the space between fixed text and dynamic meaning, literary theory counters signostalgia in all its forms, and thus operates as a corrective against such errors as yesternationalism. In saying so, I do not assert the grandiose claim that literary theory corrects those errors: that would depend on national culture's willingness to be corrected. I do contend, though, that literary theory operates as a corrective against those errors: it offers ongoing testimony to the non-identity of word and meaning, and thus to the inherent falsehood of signostalgia in all its forms.

\author{
H. L. Hix \\ hhix@uwyo.edu \\ Philosophy Department 3392 \\ University of Wyoming \\ Laramie, WY 82071 \\ USA
}

